\title{
Modification of polysulfone with pendant carboxylic acid functionality for ultrafiltration membrane applications
}

\author{
ANNADANAM V SESHA SAINATH ${ }^{\dagger}$,* and A V R REDDY* \\ Reverse Osmosis Division, CSIR-Central Salt and Marine Chemicals Research Institute, Bhavnagar 364 002, Gujarat, India \\ ${ }^{\dagger}$ Present Address: Organic Coatings and Polymers Division, CSIR-Indian Institute of Chemical Technology, Hyderabad \\ 500 007, Andhra Pradesh, India
}

MS received 26 October 2010; revised 4 September 2012

\begin{abstract}
Carboxyphenoxymethyl polysulfone (CPMPSF) was synthesized in two steps: (i) chloromethylation of polysulfone (PSF) by in situ generated chloromethyl radical in presence of stannic chloride in tetrachloroethane and (ii) reaction of chloromethylated PSF with $p$-hydroxybenzoic acid in presence of potassium carbonate in dimethylformamide. The structures of the modified PSFs were confirmed by elemental analysis, IR, ${ }^{1} \mathrm{H}-\mathrm{NMR}$ and ${ }^{13} \mathrm{C}-\mathrm{NMR}$ techniques. The PSF and CPMPSF based ultrafiltration membranes were prepared according to phase-inversion process using water as nonsolvent at $4^{\circ}$ and $15^{\circ} \mathrm{C}$, employing casting dope having different amounts of polymer (PSF or CPMPSF), polyvinylpyrrolidone (PVP) and solvent, dimethylformamide (DMF). The membranes were characterized for their pore size, pure water flux and flux and rejection for the permeation of different molecular weight poly(ethylene glycol) (PEG) solutions and sodium chloride $(\mathrm{NaCl})$ solution. The pore radius of the CPMPSF membrane which was prepared without PVP in the casting dope was about $222 \AA$, whereas, that of the membrane prepared in the presence of PVP $(6 \mathrm{wt} \%)$ in the casting dope was about $124 \AA$. For the PSF membranes, pore radii were $80 \AA$ (without PVP) and $176 \AA$ (with PVP 6 wt \%). The CPMPSF-based membranes exhibited higher flux and rejections for PEG and NaCl solutions, as compared to the PSF membranes, due to the presence of hydrophilic carboxylic acid group. The CPMPSF membrane exhibited about $48 \%$ rejection of $\mathrm{NaCl}$ when tested for $5000 \mathrm{ppm}$ feed solution at 400 psi.
\end{abstract}

Keywords. Modified polysulfone; ultrafiltration membranes; poly(ethylene glycol)s; flux and rejection.

\section{Introduction}

In recent years, membrane ultrafiltration has received tremendous importance as a simple and convenient technique for different applications like treatment of drinking water for the removal of microbial contamination; purification, concentration, and/or fractionation of various products in medical, biotechnological and beverage industries; water recovery from pulp and paper industry (Aptel 1994; Zeman and Zydney 1996; Ghosh 2003; Li et al 2004; Charcosset 2006). The ultrafiltration membranes generally contain an asymmetric structure in which a thin and dense top layer is supported on a porous sublayer with thickness ranging from 100 to $150 \mu \mathrm{m}$. The separation properties of the ultrafiltration membranes depend on their physicochemical properties which include pore size, pore size distribution and surface chemistry, which have considerable impact on transport characteristics, selectivity and fouling propensity of the membrane.

Many types of polymeric membranes were reported for reverse osmosis (RO), ultrafiltration (UF), microfiltration and

\footnotetext{
*Authors for correspondence (avss@ iict.res.in, avreddy@csmcri.org)
}

selective gas permeation applications (Rana and Matsuura 2010). The PSF is one of the widely employed polymers for making commercial membranes due to its high chemical resistance, thermal stability and mechanical strength (Nystrom 1989; Kim et al 2001; Dai et al 2003). However, PSF membranes are known to be prone for rapid fouling during UF of aqueous macromolecular solutions because of its hydrophobic nature. Fouling, i.e. accumulation of nonspecific matter from the feed solution on the membrane surface and pores, is an unavoidable deleterious phenomenon in the membrane process that causes large permeate flux decline with operation time followed by the deterioration of permeate quality. In order to impart hydrophilic character to UF membranes, two different approaches were generally followed: (i) surface modification of the membrane by the formation of a thin layer of a polymer having hydrophilic nature by free radical- or photo-polymerization of methacrylate monomers wherein, hydrophilic nature is incorporated only on the top surface of the membrane and (ii) covalent attachment of functional groups like $-\mathrm{COOH}, \mathrm{SO}_{3} \mathrm{H}$, etc. to the polymer backbone by appropriate chemical reactions and then preparing the membrane. The PSF membrane surface modification was achieved by atom transfer radical polymerization (Liang et al 2009), UV-induced surface graft polymerization (Deng et al 2009) and amphiphilic ABA 
copolymers (Liu et al 2004; Wang et al 2008) for antifouling and biomedical applications. Surface modification (Nagase et al 1990; Aitken et al 1992; Pixton and Paul 1995; Ghosal et al 1996; Dai et al 2002; Reddy et al 2003; Dal-cin et al 2006; Yu et al 2009) by chemical bonding of macromolecules onto the membrane or by a partly reversible chemical adsorption of the modifier onto the membrane was reported. But, surface modification partly blocks the membrane pores and hence, the total flux after the modification is not smaller than before. Modification of the PSF at molecular level could control hydrophobic and hydrophilic nature within the membrane physical structure and enhances the transport properties. Several researchers introduced various pendant functional groups to the PSF macromolecular chain and explored them for different applications. Heparinmodified PSF for hemodialysis and low-density lipoprotein removal (Xiao-Jun et al 2011), PSF having benzimine and benzylamine groups as precursors for molecularly imprinted sensor devices (Gilles et al 2003) and PSF aldehydes for reactive membranes which are having affinity to bind enzymes and ligands (Michael et al 2001) were reported. By introducing dipyridyl functionality on PSF chain, chelation of heavy metal ions such as copper and nickel from aqueous solutions was achieved (Summers et al 2001). The UF membranes based on polyethersulfone/polyacrylonitrile blend and their modification by treatment with alkali to convert the nitrile group to carboxylic acid was reported (Reddy and Patel 2008) for fouling resistance.

We herein report the modification of PSF to introduce carboxylic acid group ( $p$-carboxyphenoxymethyl) as the pendant. Further, UF membranes of both the modified and the unmodified PSF were prepared and compared their performances in terms of flux and separations by permeating aqueous solutions of different molecular weight PEGs.

\section{Experimental}

\subsection{Materials}

Polysulfone (Udel P-3500) was dried at $120^{\circ} \mathrm{C}$ for $4 \mathrm{~h}$ prior to use. Poly(ethylene glycol)s (PEG; $M_{\mathrm{w}}: 9,15,20$ and $35 \mathrm{KDa}$ ) and polyvinylpyrrolidone (PVP; $\left.M_{\mathrm{w}}: 35 \mathrm{KDa}\right)$, stannic chloride $\left(\mathrm{SnCl}_{4}\right)$ (Fluka), $p$-hydroxybenzoic acid (HBA), potassium carbonate $\left(\mathrm{K}_{2} \mathrm{CO}_{3}\right)$ and dimethylformamide (DMF) were used without purification. Acetylchloride, dimethoxy methane, dichloromethane and 1,1',2,2'tetrachloroethane were purified by distillation.

\subsection{Preparation of chloromethylpolysulfone $\left(\mathrm{PSF}-\mathrm{CH}_{2} \mathrm{Cl} \cong \mathrm{CMPSF}\right)$}

In a three-necked flask containing mechanical stirrer, reflux condenser and separating funnel; dimethoxymethane $(180 \mathrm{~mL}, 2.0 \mathrm{~mol})$ and methanol $(5 \mathrm{~mL})$ were taken and the contents were cooled at $0-5^{\circ} \mathrm{C}$. Then, acetylchloride
$(128 \mathrm{~mL}, 1.8 \mathrm{~mol})$ was added drop-wise, diluted the con-

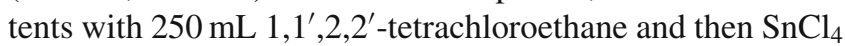
$(1 \mathrm{~mL}, 0.01 \mathrm{~mol})$ was added. The solution of PSF $(40 \mathrm{~g}$, $0.09 \mathrm{~mol})$ in $1,1^{\prime}, 2,2^{\prime}$-tetrachloroethane $(500 \mathrm{~mL})$ was then added drop-wise under stirring and reflux. After refluxing for another $10 \mathrm{~h}$, the reaction was quenched by adding $5 \mathrm{~mL}$ water. The volume of the reaction mixture was reduced to $200 \mathrm{~mL}$ by distilling off the solvent and then added to methanol to precipitate out CMPSF. It was filtered and purified by reprecipitation in methanol from the solution in chloroform, and finally dried at $120^{\circ} \mathrm{C}$. The CMPSF was characterized by elemental analysis, IR, ${ }^{1} \mathrm{H}-\mathrm{NMR}$ and ${ }^{13} \mathrm{C}-\mathrm{NMR}$ techniques.

\subsection{Preparation of p-carboxyphenoxymethyl polysulfone $\left(\mathrm{PSF}-\mathrm{CH}_{2} \mathrm{OC}_{6} \mathrm{H}_{4}-\mathrm{COOH} \cong \mathrm{CPMPSF}\right)$}

The solution of CMPSF (22 g, $0.04 \mathrm{~mol})$ in DMF $(250 \mathrm{~mL})$ was prepared and added drop-wise to a well stirred and refluxing solution of HBA $(11.3 \mathrm{~g}, 0.08 \mathrm{~mol})$ and $\mathrm{K}_{2} \mathrm{CO}_{3}$ $(33.9 \mathrm{~g}, 0.24 \mathrm{~mol})$ in DMF $(50 \mathrm{~mL})$. The mixture was refluxed for another $10 \mathrm{~h}$ and then poured into excess methanol. The CPMPSF thus precipitated was filtered, washed with water, dilute $\mathrm{HCl}$ solution and methanol. After drying, the polymer was dissolved in chloroform and reprecipitated in methanol for purification. The polymer was characterized by elemental analysis, IR, ${ }^{1} \mathrm{H}-\mathrm{NMR}$ and ${ }^{13} \mathrm{C}-$ NMR techniques.

\subsection{UF membrane preparation}

The PSF/CPMPSF solution in DMF was prepared and cast a film of about $300 \mu$ thickness on a glass plate $(20 \times 30 \mathrm{~cm}$ size) using doctor's knife at an ambient temperature. After about 15 or $45 \mathrm{~s}$, the glass plate containing the liquid polymer film was immersed in a water bath containing $10 \%$ (v/v) DMF at 4 or $15^{\circ} \mathrm{C}$. This has resulted in the formation of membrane by phase inversion of the polymer solution through solvent-non-solvent exchange process. The membrane was washed with water and preserved in pure water at room temperature. Table 1 gives the details of UF membrane preparation conditions.

\subsection{UF measurements}

The membranes were cut into disks $(7.5 \mathrm{~cm}$ diameter $)$ and tested them in a dead-end stirred cell assembly (Amicon model) at $25-45 \mathrm{psi}$ pressure using compressed air. The membranes were first compacted for 20 min at 45 psi by permeation of pure water flux. Then, the flux for the permeation of 250-1000 ppm aqueous PEG solutions was measured 4-5 times. The PEG concentration in the feed and permeate was determined by gel permeation chromatography. The flux was calculated using the following equation:

Flux $(J)=V / A t$, 
Table 1. Composition of polymer solutions for membrane casting.

\begin{tabular}{|c|c|c|c|c|c|c|}
\hline Membrane code & Polymer & $\begin{array}{l}\text { Polymer } \\
(\mathrm{wt} \%)\end{array}$ & $\begin{array}{l}\text { PVP } \\
(\mathrm{wt} \%)\end{array}$ & $\begin{array}{l}\text { DMF } \\
(w t \%)\end{array}$ & $\begin{array}{l}\text { Evaporation time } \\
\text { (s) }\end{array}$ & $\begin{array}{c}\text { Gelation bath }{ }^{\mathrm{a}} \\
\text { temperature }\left({ }^{\circ} \mathrm{C}\right)\end{array}$ \\
\hline CPMPSF16 & CPMPSF & 16 & 0 & 84 & 0 & 15 \\
\hline CPMPSF16PVP06 & CPMPSF & 16 & 6 & 78 & 0 & 15 \\
\hline CPMPSF20 & CPMPSF & 20 & 0 & 80 & 45 & 4 \\
\hline PSF16PVP06 & PSF & 16 & 6 & 78 & 0 & 15 \\
\hline PSF16 & PSF & 16 & 0 & 84 & 0 & 15 \\
\hline PSF20 & PSF & 20 & 0 & 80 & 45 & 4 \\
\hline
\end{tabular}

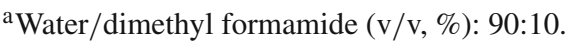

where $J$ is the water/permeate flux $\left(\mathrm{L} / \mathrm{m}^{2} \mathrm{~h}\right), V$ the volume of water permeated $(\mathrm{L}), A$ the membrane area $\left(\mathrm{m}^{2}\right)$ and $t$ the permeation time $(\mathrm{h})$. The solute rejection was calculated using the following equation:

$$
\text { Solute rejection }=\left[1-\left(C_{\mathrm{p}} / C_{\mathrm{f}}\right)\right] \times 100,
$$

where $C_{\mathrm{p}}$ and $C_{\mathrm{f}}$ are concentrations of the solute in permeate and feed, respectively.

\subsection{RO measurements}

The RO measurements were performed in a standard test kit consisting of high pressure pump, pressure and flow regulating valves and four cells $(4.8 \mathrm{~cm}$ diameter each) connected in a series. The membranes were initially compacted for $30 \mathrm{~min}$ at $600 \mathrm{psi}$, measured pure water permeation rate at $500 \mathrm{psi}$ and then tested using $5000 \mathrm{ppm} \mathrm{NaCl}$ feed solution at $500 \mathrm{psi}$. The salt concentration in permeate was determined by measuring the conductivity and the salt rejection was calculated as per (2) from $\mathrm{NaCl}$ concentrations in permeate and feed solutions.

\subsection{Analytical techniques}

Elemental analysis was performed with Coleman $\mathrm{C}-\mathrm{H}-\mathrm{N}$ analyser. IR spectra of the polymer films were obtained with a BIO-RAD FTS-40 IR spectrophotometer. NMR spectra were recorded with a JEOL-JNM-FX-100 FT NMR spectrometer using $\mathrm{CDCl}_{3}$ as solvent and tetramethylsilane as the internal standard. Water gel permeation chromatography (Model 501) with ultra-hydrogel columns was used for the determination of PEG concentration in feed and permeate.

\subsection{Membrane average pore radius}

Using pure water permeation rates, UF membrane pore radius $(r)$ was calculated according to Poiseuille's law as follows:

$$
\begin{aligned}
& \text { Pore radius }(r, \AA)=\sqrt{ }\left\{\left(8 / P_{\mathrm{o}}\right) K_{\mathrm{p}}\right\}, \\
& P_{\mathrm{o}}=\left\{\left(W_{\mathrm{e}}-W_{\mathrm{d}}\right) /(A L \rho w)\right\}=\pi \mathrm{r}^{2} \eta, \\
& K_{\mathrm{p}}=(\eta L Q) /(A \Delta P),
\end{aligned}
$$

where $P_{\mathrm{o}}$ is the porosity; $K_{\mathrm{p}}$ the specific permeability $\left(\mathrm{cm}^{2}\right)$; $W_{\mathrm{e}}$ the weight of the wet membrane $(\mathrm{g}) ; W_{\mathrm{d}}$ the weight of the dry membrane (g); $A$ the effective membrane area $\left(\mathrm{cm}^{2}\right)$; $L$ the membrane thickness $(\mathrm{cm}) ; \rho w$ the density of water $\left(\mathrm{g} / \mathrm{cm}^{2}\right) ; \eta$ the viscosity of water $\left(\mathrm{dy} / \mathrm{cm}^{2} / \mathrm{s}\right) ; Q$ the water permeation rate $\left(\mathrm{cm}^{3} / \mathrm{s}\right)$ and $\Delta P$ the pressure difference across the membrane $\left(\mathrm{dy} / \mathrm{cm}^{2}\right)$.

\section{Results and discussion}

\subsection{PSF modification}

The CPMPSF was synthesized in two steps as shown in scheme 1. In the first step, CMPSF was prepared by reacting PSF with in situ generated chloromethyl radical at
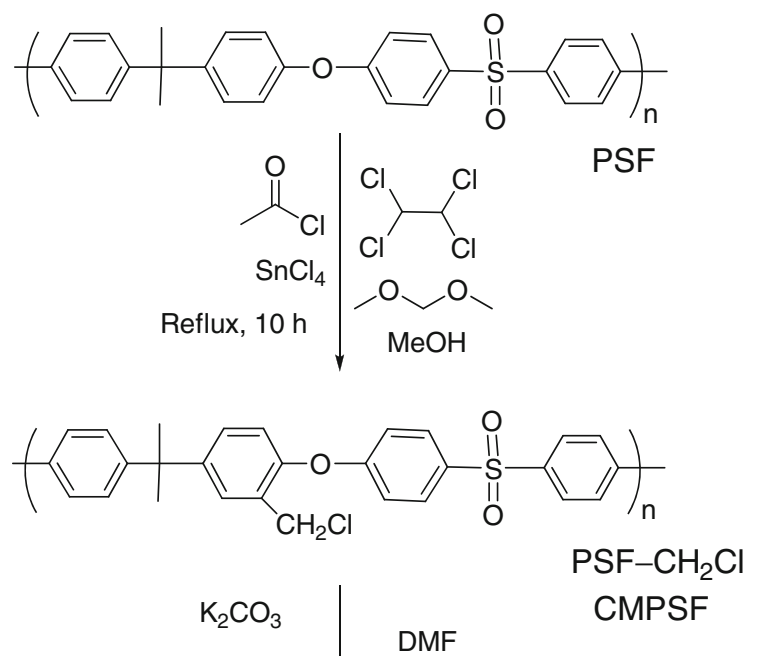<smiles>O=C(O)c1ccc(O)cc1</smiles><smiles>CC(C)(C)c1ccc(COC(=O)COC(=O)c2ccc(OCc3cc(C(C)(C)c4ccc(C(C)(C)C)cc4)ccc3Oc3ccc(S(=O)(=O)c4ccc(C(C)(C)C)cc4)cc3)cc2)cc1</smiles>

Scheme 1. Synthesis of CPMPSF. 
Table 2. Characteristics of CMPSF and CPMPSF.

\begin{tabular}{llc}
\hline Characterization & \multicolumn{1}{c}{ CMPSF } & CPMPSF \\
\hline CHN analysis $(\%)$ & Found: $\mathrm{C}, 69 \cdot 30 ; \mathrm{H}, 4 \cdot 77$ & Found: $\mathrm{C}, 71 \cdot 27 ; \mathrm{H}, 4 \cdot 80$ \\
$\mathrm{IR}\left(\mathrm{cm}^{-1}\right)$ & $735\left(\mathrm{Cl}-\mathrm{CH}_{2}-\right)$ & $1725(\mathrm{ester} \mathrm{C}=\mathrm{O}) ; 3250-3400(\mathrm{broad},-\mathrm{COOH})$ \\
${ }^{1} \mathrm{H}-\mathrm{NMR}(\mathrm{ppm})$ & $7 \cdot 9(\mathrm{Ar}-\mathrm{H}, \mathrm{d}, 4 \mathrm{H}) ; 7 \cdot 3(\mathrm{Ar}-\mathrm{H}, \mathrm{d}, 4 \mathrm{H}) ;$ & $7 \cdot 9(\mathrm{Ar}-\mathrm{H}, \mathrm{d}, 4 \mathrm{H}) ; 7 \cdot 3(\mathrm{Ar}-\mathrm{H}, \mathrm{d}, 4 \mathrm{H}) ;$ \\
& $6 \cdot 9(\mathrm{Ar}-\mathrm{H}, \mathrm{m}, 7 \mathrm{H}) ; 4 \cdot 4\left(-\mathrm{CH}_{2}-, \mathrm{s}, 2 \mathrm{H}\right) ;$ & $6 \cdot 9(\mathrm{Ar}-\mathrm{H}, \mathrm{m}, 11 \mathrm{H}) ; 4 \cdot 5\left(-\mathrm{CH} \mathrm{H}_{2}-\mathrm{s}, 2 \mathrm{H}\right) ;$ \\
${ }^{13} \mathrm{C}-\mathrm{NMR}(\mathrm{ppm})$ & $1 \cdot 6\left(-\mathrm{CH}_{3}, \mathrm{~s}, 6 \mathrm{H}\right)$ & $1 \cdot 7\left(-\mathrm{CH}_{3}, \mathrm{~s}, 6 \mathrm{H}\right)$ \\
& $162 \cdot 4,153 \cdot 3,147 \cdot 6,140 \cdot 2,135 \cdot 8,130 \cdot 1$, & $162 \cdot 5,153 \cdot 3,147 \cdot 6,141 \cdot 5,138 \cdot 7,135 \cdot 9$, \\
& $128 \cdot 9,120 \cdot 2$ and $118 \cdot 8(\mathrm{Ar}-\mathrm{C}) ; 69 \cdot 5\left(-\mathrm{CH}_{2}-\right) ;$ & $130 \cdot 2,129 \cdot 0,120 \cdot 3$ and $118 \cdot 2(\mathrm{Ar}-\mathrm{C}) ;$ \\
& $42 \cdot 8(>\mathrm{C}<) ; 31 \cdot 5\left(-\mathrm{CH}_{3}\right)$ & $76 \cdot 2\left(-\mathrm{CH}_{2}-\right) ; 42 \cdot 9(>\mathrm{C}<) ; 31 \cdot 5(-\mathrm{CH})$ \\
\hline
\end{tabular}

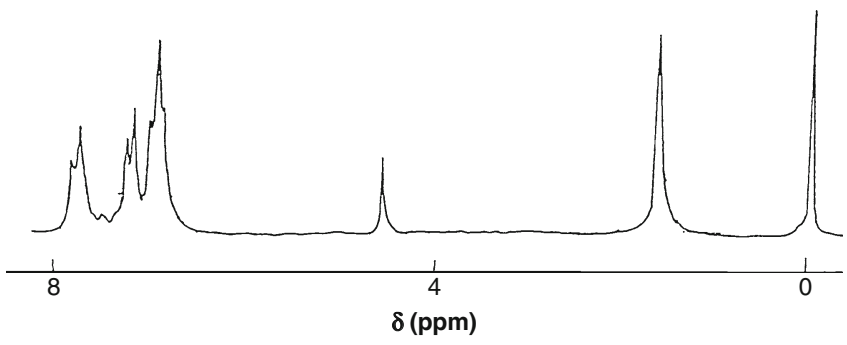

Figure 1. ${ }^{1} \mathrm{H}-\mathrm{NMR}$ spectrum of CPMPSF.

reflux temperature. The CMPSF was then reacted with HBA to obtain CPMPSF. The structures of both CMPSF and CPMPSF were confirmed by elemental analysis, IR, ${ }^{1} \mathrm{H}-$ NMR and ${ }^{13} \mathrm{C}-\mathrm{NMR}$ techniques (table 2). The ${ }^{1} \mathrm{H}-\mathrm{NMR}$ spectrum of CPMPSF (figure 1) shows resonance signals at 7.9-7.0 ppm due to aromatic protons of PSF and pendant carboxyphenyl group. The peak at about $4.2 \mathrm{ppm}$ corresponds to $\mathrm{CH}_{2}$ protons present in the pendant, which was absent in the virgin PSF. The methyl protons of the isopropylidene group appeared as singlet at $1.7 \mathrm{ppm}$. In the ${ }^{13} \mathrm{C}-\mathrm{NMR}$ spectrum of CPMPSF (figure 2), signals due to aromatic carbons appeared at 162.5, 153.3, 147.6, 141.5, 138.7, 135.9, $130 \cdot 2,129 \cdot 0,120 \cdot 3$ and $118 \cdot 2 \mathrm{ppm}$. The aliphatic carbon signals were observed at $76.2 \mathrm{ppm}\left(-\mathrm{CH}_{2}-\right), 42.9 \mathrm{ppm}(>\mathrm{C}<)$ and $31.5 \mathrm{ppm}\left(-\mathrm{CH}_{3}\right)$. From the ${ }^{1} \mathrm{H}-\mathrm{NMR}$ and elemental analysis data, it was found that the extent of chloromethyl and carboxyphenyl groups introduction were about 0.82 and 0.65 mole fraction per the repeat unit of PSF chain, respectively.

\subsection{UF membrane preparation and characterization}

The PSF and CPMPSF based UF membranes $(20 \times 30 \mathrm{~cm}$ size) were cast on a glass plate according to phase inversion process using casting dope containing different amounts of polymer, PVP and DMF as given in table 1 . When the glass plate containing polymer solution layer was immersed in gelation bath and phase inversion of the polymer in the solution in DMF to solid state was occurred by the exchange of DMF and water, which is a non-solvent for the polymer, and thus resulting in the formation of UF membrane. The resultant membrane contains an integrally skinned asymmetric structure, i.e. homogeneous skin and support layers of

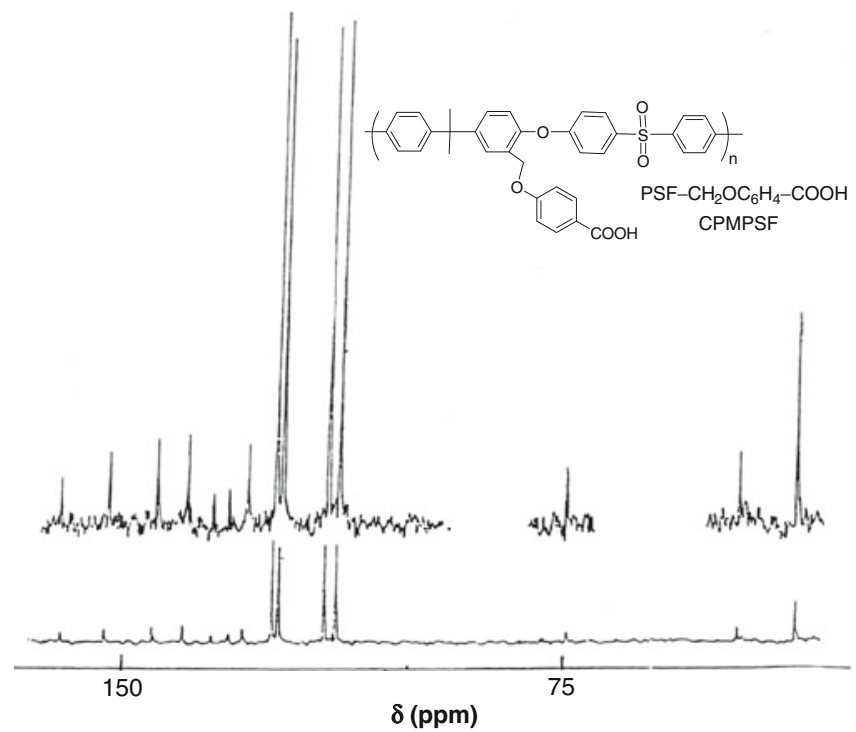

Figure 2. ${ }^{13} \mathrm{C}-\mathrm{NMR}$ spectrum of CPMPSF.

the same polymer, in which the thin and dense top layer is supported on a porous sub-layer with thickness of about $150 \mu \mathrm{m}$. The separation properties of the membranes depend on preparation conditions such as casting dope composition and residence time of the cast solution in air, which affect the membrane pore size.

The data in table 3 show that the addition of PVP in the casting dope of PSF caused an increase in the pore size of the resultant membranes. However, interestingly, for the same amount of PVP in the casting dope of CPMPSF, membrane with reduced pore size was obtained. The presence of PVP in the casting dope affects the kinetics of the phase separation of the polymer and hence the difference in the pore size of the membrane. In the presence of PVP, two factors generally influence the membrane structure formation: (i) formation of the polymer-PVP micro-emulsion due to their incompatibility in polar aprotic solvents and (ii) variations in the physicochemical properties of the membrane-forming polymer, i.e. enhancement of the hydrophilic properties. Hence, the difference in the effect of PVP in the casting dope on the pore sizes of PSF and CPMPSF membranes may be attributed to the variation in the kinetics of their phase separation due to the difference in their hydrophilic nature. In the case of hydrophobic polymers, the addition of PVP in the casting 
Table 3. The PWF of UF membranes at various pressures.

\begin{tabular}{lcrrr}
\hline & & \multicolumn{2}{c}{ PWF (LMH) at pressure (psi) } \\
\cline { 3 - 5 } Membrane code & $\begin{array}{c}\text { Average pore } \\
\text { radius (A) }\end{array}$ & 25 & 35 & \multicolumn{1}{c}{45} \\
\hline CPMPSF16 & 124 & 151 & 156 & 197 \\
CPMPSF16PVP06 & 222 & 525 & 588 & 694 \\
PSF16 & 80 & 39 & 56 & 70 \\
PSF16PVP06 & 176 & 253 & 279 & 337 \\
\hline
\end{tabular}

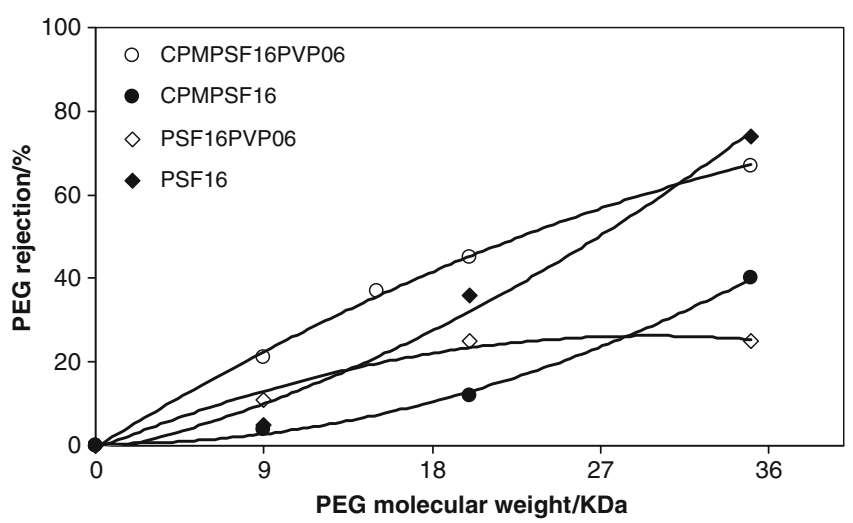

Figure 3. PEG molecular weight vs rejection at 35 psi pressure for $1000 \mathrm{ppm}$ solution at room temperature.

dope results in the formation of open-pore structure with interconnected pores due to the complete removal of water soluble PVP from the polymer matrix during phase inversion. The decrease in the membrane pore size with the addition of PVP in the CPMPSF casting dope may be explained due to the existence of intermolecular attractions, i.e. intermolecular hydrogen bonding between the carboxylic acid hydrogen of PSF- $\mathrm{CH}_{2} \mathrm{OC}_{6} \mathrm{H}_{4}-\mathrm{COOH}$ and carbonyl group of PVP. In the formation of porous membrane by phase inversion process by solvent-non-solvent exchange process in the gelation bath, the intermolecular attractions between CPMPSF and PVP appear to reduce the rate of leaching out of PVP from the polymer matrix, decreased the kinetics of the phase inversion process and thus resulted in the formation of membrane with reduced macrovoids and smaller pore size.

Pure water flux (PWF) is an important characteristic of UF membranes as it is related to pore size, porosity and hydrophilic nature of the membrane. It was observed (table 3) that the PWF of the CPMPSF membranes is significantly higher (2-4 times) than that of the unmodified PSF membranes. Since the membranes were prepared under same conditions, the higher water flux of the CPMPSF membranes may be attributed to the increased hydrophilicity of the polymer due to the presence of pendant hydrophilic carboxylic acid group which favours the formation of interfacial water at the membrane surface.

The performance of UF membrane is defined in terms of two factors namely flux and retention for the permeation of different molecular weight polymers. It was observed that the flux of both PSF and CPMPSF membranes was

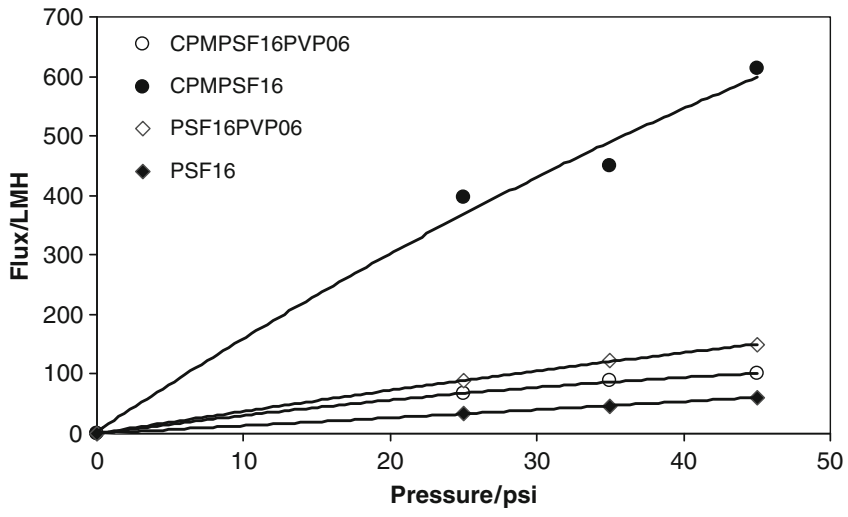

Figure 4. Pressure vs flux for PEG-35KDa, $1000 \mathrm{ppm}$ solution at room temperature.

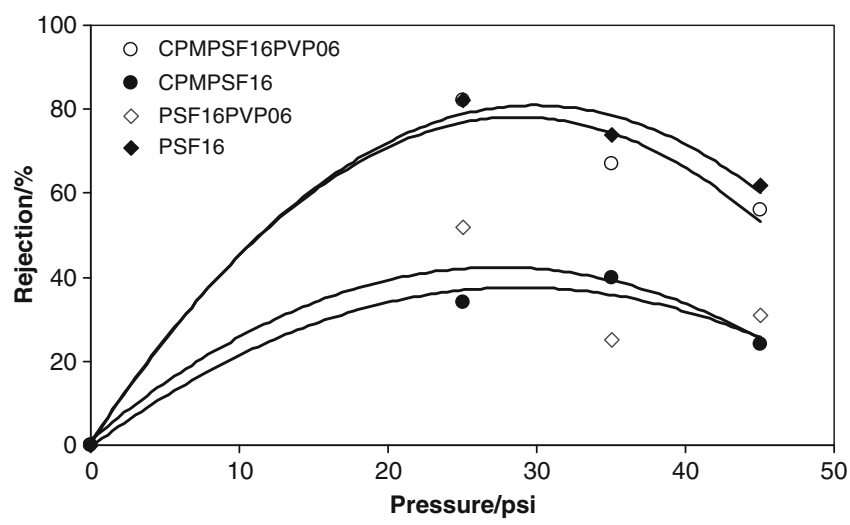

Figure 5. Pressure vs PEG-35KDa rejection for $1000 \mathrm{ppm}$ solution at room temperature.

decreased with increase in the PEG molecular weight and also with the increase of PEG concentration in the feed solution at different operating pressures. The decrease in flux with the increase in PEG concentration may be attributed to the increase in feed solution viscosity and consequently the decreased effective operative pressure. The flux decrease was large in the case of CPMPSF16 and PSF16PVP06 membranes, which have comparatively larger pore sizes than the CPMPSF16PVP06 and PSF16 membranes with comparatively smaller pore size. Upon increasing the PEG$35 \mathrm{KDa}$ concentration from 250 to $1000 \mathrm{ppm}$ in the feed, the flux was decreased from 534 to $396 \mathrm{~L} / \mathrm{m}^{2} \mathrm{~h}$ (LMH) for CPMPSF16; 182-88 LMH for PSF16PVP06 and 78-66 LMH for CPMPSF16PVP06 at 25 psi. However, the flux of PSF16 was about 34 LMH and almost remains unchanged with the increase of feed concentration. In the UF of aqueous solution of polymers, it was commonly observed that the flux reduction of the membranes with larger pore sizes was much greater than the membranes having relatively smaller pore sizes (Reddy et al 2003). This type of behaviour of the membranes is usually attributed to two different phenomena which occur simultaneously during UF process. When the membrane pore size is larger than solute size, there is a greater possibility that the solute molecules enter the pores 
but may not be able to come out due to the lack of interconnectivity of pores with concomitant decrease in flux due to pore blocking. Another phenomenon that causes higher decrease in permeate flux is concentration polarization at the surface as membranes with larger pore size have higher permeation rates and hence causes rapid increase in the feed concentration at the membrane surface.

Figure 3 shows the variation of membrane rejection with PEG molecular weight in the feed solution. For all membranes, the rejection was increased with increasing the molecular weight of the PEG. The CPMPSF16PVP06 and PSF16 membranes exhibited about $70 \%$ rejection for PEG-35KDa. However, there was a huge difference in the rejection of the same membranes for low molecular weight PEG (PEG-9KDa), with rejections of about 20 and 5\% for CPMPSF16PVP06 and PSF16, respectively. The CPMPSF16 and PSF16PVP06 membranes exhibited about 40 and $25 \%$ rejection, respectively, for PEG-35 KDa. The data clearly indicate that CPMPSF16PVP06 has smaller molecular weight cut-off than the other three membranes. The flux was increased (figure 4) with the increase of applied pressure due to the increase in net driving force, which is commonly observed in all the membrane separations. The rejection of PEG-35KDa was decreased (figure 5) with increasing the applied pressure. The decrease in rejection was more pronounced in the case of membranes with larger pore size than those of with smaller pore size. This may be attributed to the fact that higher flux rates (higher recovery) at higher pressures result in the build up of solute concentration at the membrane surface, which eventually causes a decrease in the solute rejection.

\subsection{RO membrane performances}

The salt rejection of CPMPSF16, CPMPSF20 and PSF20 membranes were determined using $5000 \mathrm{ppm} \mathrm{NaCl}$ feed solution at 400 psi. It was observed that PSF20 membrane did not show any rejection for $\mathrm{NaCl}$. However, CPMPSF16 and CPMPSF20 exhibited salt rejection of 8 and 32\%, respectively. On annealing the membranes at $75^{\circ} \mathrm{C}$ for $90 \mathrm{~s}$, the salt rejection of CPMPSF20 was increased from 32 to $48 \%$. Further annealing for longer times at 75 and $90^{\circ} \mathrm{C}$ did not improve the salt rejection. Similarly annealing treatment on CPMPSF16 had no effect on its salt rejection. The salt rejection of CPMPSF membranes may be attributed to the presence of pendant carboxylic acid which imparts both hydrophilicity and negative charge to the membrane.

\section{Conclusions}

The PSF containing pendant $p$-carboxyphenoxymethyl group was prepared by chloromethylation of PSF followed by treating with HBA. The UF of both the virgin and modified PSFs were prepared according to phase inversion process under different conditions. The average pore radii of the membrane dependents on the concentration of the polymer solution as well as the presence of PVP in the casting dope. The presence of PVP in casting dope caused the decrease in the pore size of CPMPSF membranes whereas, an opposite trend was observed in the case of PSF membranes, thus indicating the effect of the presence of hydrophilic carboxylic acid group on the membrane formation.

\section{References}

Aitken C L, Koros W J and Paul D R 1992 Macromolecules 253651 Aptel P 1994 Membrane process in separation and purification (eds) J G Crespo and K W Boddeker (Dordrecht, The Netherlands: Kluwer Academic Publishers)

Charcosset C 2006 Biotech. Adv. 24482

Dai Y, Guivel M D, Robertson G P, Bilodeau F, Kang Y S, Lee K J, Jho J Y and Won J 2002 Polymer 435369

Dai Y, Guiver M D, Robertson G P, Kang Y S and Lee K J 2003 Macromolecules 366807

Dal-cin M M, Guiver M D, Striez C N, Carlsson D J and Kumar A 2006 J. Appl. Polym. Sci. 1011723

Deng J P, Wang L F, Liu L Y and Yang W T 2009 Prog. Polym. Sci. 341156

Ghosal K, Chern R T, Freeman B D, Daly W H and Negulescu I I 1996 Macromolecules 294360

Ghosh R 2003 Protein bioseparation using ultrafiltration: theory, application and new developments (London: Imprerical College Press)

Gilles P R, Michael D G, Francois B and Masakazu Y 2003 J. Polym. Sci: Part A: Polym. Chem. 411316

Kim I W et al 2001 Macromolecules 342908

Li S Z, Li X Y, Cui Z F and Wang D Z 2004 Sep. Purif. Technol. 34 115

Liang L, Guoping Y and Jiangyu W 2009 J. Appl. Polym. Sci. 111 1942

Liu G, Lu Z and Duncan S 2004 Macromolecules 374218

Michael D G, Hong Z, Gilles P R and Ying D 2001 J. Polym. Sci: Part A: Polym. Chem. 39675

Nagase Y, Naruse A and Matsui K 1990 Polymer 31121

Nystrom M 1989 J. Membr. Sci. 44183

Pixton M R and Paul D R 1995 Polymer 363165

Rana D and Matsuura T 2010 Chem. Rev. 1102448

Reddy A V R, Mohan D J, Bhattacharya A, Shah V J and Ghosh P K 2003 J. Membr. Sci. 214211

Reddy A V R and Patel H R 2008 Desalination 221318

Summers G J, Ndawuni M P and Summers C A 2001 Polymer 42397

Wang J Y, Xu Y Y, Zhu L P, Li J H and Zhu B K 2008 Polymer 49 3256

Xiao-Jun H, Deepak G, Zhi-Kang X, Jorg V and Thomas G 2011 Macromol. Biosci. 11131

Yu H J, Cao Y M, Kang G D, Liu J H, Li M and Yuan Q 2009 J. Membr. Sci. 3426

Zeman L Z and Zydney A L 1996 Microfiltration and ultrafiltration (New York: Marcel Dekker Inc.) 